\title{
The Quality of Life of Adults with Developmental Disabilities and Their Families in Calgary Canada: A Pilot Study
}

\author{
Mitchell Clark, Ryan Geake, Amanda D. Smith, Mickey Greiner, and Elaine Yost
}

\begin{abstract}
This pilot study investigated the level of satisfaction in a number of life domains in addition to the overall life satisfaction experienced by group of individuals with developmental disabilities in Calgary. This study also examined the quality of life of their families who are often impacted the continuing responsibilities, concerns and anxieties related to their adult child with developmental disabilities. The average ratings from the family and individual responses across the various life domains were computed. The inter-relationships between the dimensions of family quality of life across the various life domains included in the quality of life assessment were also calculated. Understanding these associations may be helpful in identifying supports and policies that enhance individual and/or family quality of life. Finally, the connections between individual and family quality of life were identified to highlight any areas where changes in supports or services to either families or their adult children with intellectual disabilities would support the wellbeing of all family members.
\end{abstract}

Index Terms-Family quality of life, well-being, developmental disability, personal well-being index, intellectual disability

\section{INTRODUCTION}

Quality of life (QoL) has been of interest for centuries, but systematic progress in clarifying this construct and in applying it to the assessment and design of services for persons with disabilities and their families has been underway for only the past couple of decades. Research and development activities led to the development of models and assessments of QoL of persons with developmental or intellectual disabilities in the early 1990s [1]-[4]. More recently, this construct has been extended to the lives of families that include persons with disabilities and has become the focus of assessment devices developed for this purpose [5]-[7].

Many of the stresses and life circumstances that undermine the subjective well-being of individuals with disabilities are well documented. A literature review provided by Lyons [8] outlines the changes in awareness of

Manuscript received February 21, 2013; revised April 22, 2013. This work was supported by a grant from the Government of Alberta CRGI Ideas Fund.

Mitchell Clark is with the Department of Psychology, and the Centre for Child Well-Being at Mount Royal University, Calgary Canada T3E 6K6 (email: mclark@mtroyal.ca).

Ryan Geake is with the Calgary SCOPE Society and Mount Royal University.

Amanda D. Smith is a graduate student at the University of Calgary.

Mickey Greiner is with the Calgary Society for Persons with Disabilities.

Elaine Yost is with Optional Rehabilitation Services (OPTIONS) Inc. the quality of life of individuals with disabilities through the decades since the 1950s and 1960s with the beginnings of the human rights movement. Through this period, there was growing appreciation of the disadvantage and marginalization experienced by most individuals with developmental disabilities. A number of movements, such as deinstitutionalization, normalization, social role valorization and integration, began in response to societal concerns over the living situations of the majority of people with intellectual disabilities (ID). These movements supported a developing focus on QoL improvement, and services and programs were evaluated based on their contribution to the enhanced well-being of program participants [8].

This pilot study investigates the level of satisfaction in a number of life domains in addition to overall satisfaction with their lives experienced by a group of individuals with developmental disabilities in Calgary, Canada. This study also examines the quality of life of their families who are often impacted by their continuing responsibilities, concerns and anxieties related to their adult child with developmental disabilities. The inter-relationship between the dimensions of family quality of life across the various life domains included in the quality of life assessment are described in the Results section. Understanding these associations may be helpful in identifying supports and policies that enhance individual and/or family quality of life. Finally, the connections between individual and family quality of life are identified to highlight any areas where changes in supports or services to either families or their adult children with intellectual disabilities would support the well-being of all family members.

\section{METHOD}

\section{A. Participants}

Twenty (20) individuals and 19 families were recruited from among the individuals receiving services from three Calgary-based disability-serving agencies.

Of the 20 individuals surveyed, the survey responses provided by thirteen of the participants met the criteria for inclusion in the study.

\section{B. Instruments}

The Family Quality of Life Survey [9] includes nine domains are as follows: (1) Health; (2) Financial well-being; (3) Family relations; (4) Support from other people; (5) Support from disability-related services; (6) Spiritual and cultural values; (7) Careers and preparation for careers; (8) Leisure and recreation; and (9) Community involvement. 
For each of these domains family respondents provided ratings across six dimensions (Importance, Opportunities, Initiative, Stability, Attainment, and Satisfaction).

The Personal Well-being Index - Intellectual Disability (PWI-ID) scale [10] is a quality of life instrument that is one of several parallel forms of the Personal Well-being Index. All of the forms of the PWI measure subjective well-being across seven domains: (1) standard of living, (2) personal health, (3) achievement in life, (4) personal relationships, (5) personal safety, (6) community connectedness, and (7) future security; as well as the broader concept of "life as a whole."

\section{Procedure}

The purpose of the survey and process to be used was described to individuals receiving service through participating agencies. They were assured that if they were interested in participating, their responses would be held in strict confidence and they could change their mind at any time.

Families of those individuals who were interested in participating were contacted. In addition to requesting their approval they were also asked if they were willing to participate in the study.

Five interviewers were recruited to conduct the interviews with both the participating individuals with disabilities and their families. The interviewers all had experience working with persons with disabilities and their families. All the interviewers received training to prepare them for the use of the survey forms for both families and individuals.

\section{RESULTS}

Twenty family members from 19 families participated in the interviews which followed the Family Quality of Life (FQoL) survey form. The adult children of these families also participated in separate interviews conducted using the PWI-ID although meaningful results were obtained from only 13 of these individuals.

The adult children with ID in these families ranged in age from 21 up to 62 years and demonstrated varying levels of support needs and communications abilities. Of the individuals with developmental disabilities included in the results, only two were living in the family home. At the same time, eight family members indicated they found the level of responsibility they had for the individual with ID to be "more" or "much more" than they would like, suggesting that they felt stressed in relation to the support needs of the individual with ID in their family.

Table I provides a description of the outcomes of the Family QoL survey. Note that ratings on all of the domains are out of a total possible of 5.00 for each item.

As is usually the case in surveys of family quality of life, all of the domains of family life are seen as important. The pattern of relative importance across the domains provides some unusual results when compared to other studies using the FQoL survey. In particular the rating of service supports (4.94) and its rank in third place (very close behind the "Health" and "Family" domains) suggests how critical these services are seen for family well-being. This indicates a much stronger focus on formal services than is typical in other studies. In spite of the importance of these support services to families, they viewed these services as most likely to decline in the near future in comparison to all of the other domains. This situation is suggestive of the anxiety felt by families that services may be under threat due to possible government cut backs or shifting priorities. Other domains that are rated as more likely to decline include Careers (a domain that is also responsive to economic downturns) and Health. The view that family health is expected to decline is likely related to the age of many of the respondents.

Support from others, while viewed as relatively important (3.47), was seen as the least important of all of the dimensions of FQoL. Families indicated there are relatively few opportunities to secure Support from Others (opportunities $=2.79$ ) and rate their efforts to establish Support from Others (2.06) as the lowest in comparison to all of the other domains. Their actual attainment of Support from Others is even lower (1.78), indicating families experience limited support other than through more formal supports, the stability of which, as noted above, cause them significant concern.

TABLE I: MEAN SCORES AND SDS FOR THE SIX FAMILY QUALITY OF LIFE

\begin{tabular}{|c|c|c|c|c|c|c|}
\hline 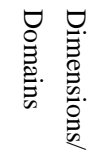 & 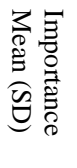 & 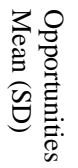 & 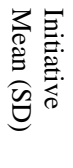 & 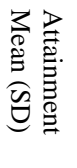 & 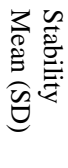 & 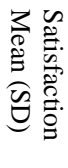 \\
\hline $\begin{array}{l}\frac{\mathbb{T}}{8} \\
\stackrel{\Xi}{E} \\
\stackrel{5}{F}\end{array}$ & $\begin{array}{l}5.00 \\
(.00)\end{array}$ & $\begin{array}{l}4.05 \\
(.71)\end{array}$ & $\begin{array}{l}4.05 \\
(.71)\end{array}$ & $\begin{array}{l}4.21( \\
.54)\end{array}$ & $\begin{array}{l}2.79 \\
(.63)\end{array}$ & $\begin{array}{l}3.95 \\
(.52)\end{array}$ \\
\hline 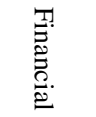 & $\begin{array}{l}4.53 \\
(.70)\end{array}$ & $\begin{array}{l}3.61 \\
(1.3)\end{array}$ & $\begin{array}{l}3.83 \\
(.1 .2)\end{array}$ & $\begin{array}{l}3.94 \\
(.90)\end{array}$ & $\begin{array}{l}3.11 \\
(.76)\end{array}$ & $\begin{array}{l}3.84 \\
(.77)\end{array}$ \\
\hline 㟒 & $\begin{array}{l}4.95 \\
(.23)\end{array}$ & $\begin{array}{l}3.84 \\
(.69)\end{array}$ & $\begin{array}{l}3.95 \\
(.71)\end{array}$ & $\begin{array}{l}4.21 \\
(.79)\end{array}$ & $\begin{array}{l}3.05 \\
(.74)\end{array}$ & $\begin{array}{l}4.11 \\
(.81)\end{array}$ \\
\hline 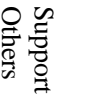 & $\begin{array}{l}3.47 \\
(1.3)\end{array}$ & $\begin{array}{l}2.79 \\
(1.4)\end{array}$ & $\begin{array}{l}2.06 \\
(1.1)\end{array}$ & $\begin{array}{l}1.78 \\
(.94)\end{array}$ & $\begin{array}{l}3.11 \\
(.47)\end{array}$ & $\begin{array}{l}3.53 \\
(.68)\end{array}$ \\
\hline 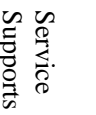 & $\begin{array}{l}4.94 \\
(.24)\end{array}$ & $\begin{array}{l}4.06 \\
(1.0)\end{array}$ & $\begin{array}{l}4.00 \\
(1.1)\end{array}$ & $\begin{array}{l}4.12 \\
(.70)\end{array}$ & $\begin{array}{l}2.56 \\
(.62)\end{array}$ & $\begin{array}{l}3.94 \\
(1.2)\end{array}$ \\
\hline 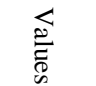 & $\begin{array}{l}3.89 \\
(1.1)\end{array}$ & $\begin{array}{l}3.42 \\
(1.2)\end{array}$ & $\begin{array}{l}2.95 \\
(1.4)\end{array}$ & $\begin{array}{l}3.32 \\
(1.1)\end{array}$ & $\begin{array}{l}3.05 \\
(.23)\end{array}$ & $\begin{array}{l}3.84 \\
(.50)\end{array}$ \\
\hline $\begin{array}{l}\Omega \\
\cong \\
\varnothing \\
\frac{\Phi}{\infty}\end{array}$ & $\begin{array}{l}4.67 \\
(.59)\end{array}$ & $\begin{array}{l}4.00 \\
(1.2)\end{array}$ & $\begin{array}{l}3.39 \\
(1.5)\end{array}$ & $\begin{array}{l}4.06 \\
(1.3)\end{array}$ & $\begin{array}{l}2.78 \\
(1.1)\end{array}$ & $\begin{array}{l}4.00 \\
(1.2)\end{array}$ \\
\hline $\begin{array}{l}\frac{5}{9} . \\
\vdots \\
0 \\
0\end{array}$ & $\begin{array}{l}4.05 \\
(.91)\end{array}$ & $\begin{array}{l}4.00 \\
(1.1)\end{array}$ & $\begin{array}{l}3.47 \\
(1.1)\end{array}$ & $\begin{array}{l}3.26 \\
(1.2)\end{array}$ & $\begin{array}{l}3.21 \\
(.42)\end{array}$ & $\begin{array}{l}3.79 \\
(1.0)\end{array}$ \\
\hline 尽 & $\begin{array}{l}4.16 \\
(1.1)\end{array}$ & $\begin{array}{l}4.05 \\
(1.1)\end{array}$ & N/A & $\begin{array}{l}3.26 \\
(.99)\end{array}$ & $\begin{array}{l}3.11 \\
(.32)\end{array}$ & $\begin{array}{l}3.84 \\
(.96)\end{array}$ \\
\hline
\end{tabular}

Note: Due to an error in the data collection form, ratings for the initiative dimension of the Community Domain were not collected.

The mean ratings of satisfaction with the various life domains and their inter-correlations were computed between 
all of the variables measured by the two instruments used in this study. Family responses about different areas of life were sometimes related to one another. A few of the interrelationships related to supports available to the family are identified below:

- People who felt strongly that their family member's needs for disability supports were met were also happiest with their family's health.

- Those who were happier with their disability services and financial opportunities also had a better quality of life.

- People who felt that disability services would get worse also saw support from others as more important.

- People who were happier about their family relationships, the support they got from others, their leisure activities and their community involvement were also more likely to see family health as stable or improving soon.

- People who had more opportunities to get disability services for their family member also had more opportunities for leisure activities and community involvement.

- People said if they had less support from extended family and friends in the future, their community involvement would be reduced and their spiritual or cultural values would have less impact on their quality of life.

- People who had more opportunities to get disability services for their family member also had more opportunities for leisure activities and community involvement.

TABLE II: MEAN SCORES AND SDS FOR THE SEVEN PERSONAL WELLBEING DOMAINS FROM THE PWI-ID ( $=13)$

\begin{tabular}{|c|c|c|}
\hline Well-being Domain & Mean & $\mathrm{SD}$ \\
\hline Life as a Whole & 8.3 & 1.84 \\
\hline Standard of Living & 8.6 & 2.26 \\
\hline Personal Health & 7.31 & 2.75 \\
\hline Achievement & 8.5 & 1.81 \\
\hline $\begin{array}{l}\text { Personal } \\
\text { Relationships }\end{array}$ & 8.2 & 2.42 \\
\hline Personal Safety & 8.3 & 2.06 \\
\hline Part of Community & 8.5 & 1.98 \\
\hline Future Security & 7.8 & 3.17 \\
\hline
\end{tabular}

The PWI-ID results (see Table II above) indicated participants were relatively happy with all of the life domains included in the survey. Their subjective sense of well-being was strongest in regard to their Standard of
Living, their Achievement goals, and feeling part of their Community. The areas that had the lowest ratings were Personal Health and their feelings about their Future Security. These areas also demonstrated the greatest variability, indicating that while some individuals were very happy with these two aspects of their life, others were somewhat unhappy in these domains.

Inter-relationships between the families' ratings of their quality of life and the well-being of their adult children with intellectual disabilities were calculated. A number of significant associations were noted. The families' level of satisfaction with their Health and Family relationships were both related to their child's rating of their life as a whole. Also, the individuals' well-being ratings of their health were associated with their family's satisfaction in the health domain. The adult children's ratings of their personal health were also correlated with the families' attainment of disability Service Supports. In addition, the individual's rating of their Future Security was related to the importance placed on Service Supports by the family as well as the opportunities they had for these supports and their attainment of them.

\section{DISCUSSION}

Overall, the adults with developmental disabilities were happy with their lives. They were most happy about their goals, community involvement and standard of living. They were least happy about their health and their future life.

The importance of disability services to the families in this survey is clear (see Table I). These supports are viewed as critical and are associated with various components of the quality of life of families. As noted earlier, satisfaction with Service Supports is strongly associated with Health attainment in families. Various dimensions of the families' financial well-being are associated with several dimensions of the Service Supports domain. Satisfaction with family relationships is also associated with satisfaction with Service Supports. There are numerous further associations with dimensions of the Service Supports domain that suggest additional relationships between Service Supports and other aspects of family quality of life.

Disability supports are also associated with the wellbeing of their adult child with a developmental disability. Personal health and future security ratings by the survey participants with ID are related to the family ratings of the attainment of Support Services. When families said disability services were important and that their family member had good services, the adult with disabilities was more likely to see his or her future as secure.

For families of adults with developmental disabilities, the ability to get good, stable disability services was strongly related to many aspects of their quality of life, such as health and the ability to pursue a career, social support, and leisure or community involvement. When good services were not in place or were expected to get worse, aging parents must spend time and energy to meet the individual's needs. Other aspects of their quality of life (such as health, work and community involvement) suffer. Adults with disabilities were also more likely to worry about their future when families say services are lacking or insecure.

When disability supports were not secure, social support became more important to families. While the value of support from others on personal well-being is well 
established, the families responding to the survey do not see it as particularly important and they reported receiving very limited support (see Table I). This may be an area that could be developed to enhance FQoL. As well as ensuring greater awareness of the benefits of support from extended family, friends and neighbors and others, there is a need to identify barriers to establishing these connections and assist families in this process. Services should be developed to train facilitators who then work with families and individuals to develop networks made up of these informal supports. The expansion of this type of service may be quite helpful in developing new supportive relationships particularly when government cutbacks reduce the availability of agency supports.

It is hard on aging family members to have to meet the disability needs of loved ones unless they have social support. However, it may be harder to look for support from friends, extended family, neighbors or others when families have to attend to disability support needs not met by formal services. Help with developing family support networks would promote greater family health and well-being.

The results of the pilot study survey of individual wellbeing and family quality of life ratings provide valuable descriptions of both their strengths and challenges. In addition, the interrelationships between the dimensions of the various life domains surveyed, across families and individuals, provide suggestions of how responses to challenges in one domain might be supported by changes in other aspects of their lives.

\section{LIMITATIONS OF STUDY AND SUGGESTIONS FOR FURTHER RESEARCH}

There were several limitations to this study. First, the number of families and individuals surveyed provided a relatively small sample. It would have been desirable to have a larger number of individuals and families, a situation that would have provided for greater confidence in the results.

A second issue that limits the results is related to the sample that was recruited. All of the families and individuals included in this study were receiving services from agencies providing disability services and supports. Families, who were on wait-lists for services and as a result were not receiving any supports, may have very different responses. Also, those families who were personally managing the supports for their child with a disability could be expected to have very different responses, particularly in the Service Supports and, perhaps, in the Support from Others domains. There may be various differences between families that choose to utilize supports provided by formal disability services and those families who choose the family-managed care options.

Finally, the results described here are specific to the Calgary area. There may be substantial differences in the level of satisfaction across the various quality of life domains in other regions of Alberta and in other urban and rural areas across Canada and in other parts of the world.

\section{ACKNOWLEDGEMENTS}

The partners who initiated this study wish to thank the individuals and families who shared their time and experiences to help us better understand their strengths and challenges. We are also grateful to the Alberta Health Services for their funding of this project through the Collaborative Research Grant Initiative: Mental Wellness in seniors and Persons with Disabilities. We would also like to note our appreciation to the research assistants who conducted the interviews. Our thanks to Sarah Vanderveen, Kelly Hallewell, Sheri Wyllie, Jared Cooper and Kimberley Yager.

\section{REFERENCES}

[1] R. I. Brown, M. B. Bayer, and P. M. Brown, Empowerment and Developmental Handicaps: Choices and Quality of Life, Toronto, ON: Captus Press, 1992.

[2] R. I. Brown, P. M. Brown, and M. B. Bayer, "A quality of life model: new challenges arising from a six year study," in Quality of Life for Persons with Disabilities, D. Goode, Ed. Cambridge, MA: Brookline, pp. 39-56, 1994.

[3] R. L. Schalock and K. D. Keith, Quality of Life Questionnaire, Worthington, OH: IDS Publishing, 1, 1993.

[4] R. L. Schalock, "Reconsidering the Conceptualization and Measurement of Quality of Life," in Quality of Life, vol. 1, R. L. Schalock, Ed. Washington, DC: American Association on Mental Retardation, pp. 123-139, 1996.

[5] A. S. Aznar and D. G. Castanon, "Quality of life from the point of view of Latin American families: A participative research study," Journal of Intellectual Disability Research, vol. 49, pp. 784-788, 2005.

[6] R. I. Brown, J. MacAdam-Crisp, M. Wang, and G. Iarocci, "Family quality of life when there is a child with a developmental disability," Journal of Policy and Practice in Intellectual Disabilities, vol. 3, no. 4, pp. 238-245, 2006.

[7] J. Park, L. Hoffman, J. Marquis, A. P. Turnbull, D. Poston, H. Mannan, M. Wang, and L. L. Nelson, "Toward assessing family outcomes of service delivery: Validation of a family quality of life survey," Journal of Intellectual Disability Research, vol. 47, no. 4-5, pp. 367-384, 2003.

[8] G. Lyons, "Quality of Life for Persons with Intellectual Disabilities: A Review of the Literature," in Enhancing the Quality of Life of People with Intellectual Disabilities: From Theory to Practice, R. Kober, Ed., Springer, pp. 73-125, 2010.

[9] I. Brown, R. I. Brown, N. T. Baum, B. J. Isaacs, T. Myerscough, S Neikrug, D. Roth, J. Shearer, and M. Wang, Family Quality of Life Survey: Main Caregivers of People with Intellectual Disabilities, Toronto, Surrey Place Centre. 2006.

[10] R. A. Cummins and A. L. D. Lau, Personal Well-being IndexIntellectual Disability (3rd edition), Melbourne: Australian Centre on Quality of Life, Deakin University, 2005.

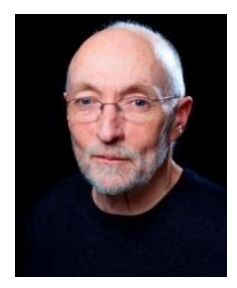

Mitchell Clark is an associate professor in the Department of Psychology at Mount Royal University in Calgary, Canada. He received his Ph.D. degree in educational psychology from the University of Calgary in Alberta, Canada. He has maintained strong community involvements having participated and led a number of boards of directors for agencies serving persons with disabilities. He has served as the Chair of the Calgary and Region Community Board for Persons with Developmental Disabilities and served on the Provincial Board for Persons with Developmental Disabilities. Dr. Clark has conducted research in the Gaza Strip focused on stress and disability among refugees, and in Malaysia on the quality of life of families that include persons with disabilities. He has also conducted international research the wellbeing of children and maintains an interest in international rehabilitation services and issues. Other interests include applied behavior analysis, computer supported learning, etiology of disabilities, and clinical psychology. He is a member of the College of Alberta Psychologists, the Canadian Psychologists Association, and the International Association for the Scientific Study of Intellectual Disabilities. 